Article

\title{
Nitrogen-Doped Porous Carbon Derived from Bamboo Shoot as Solid Base Catalyst for Knoevenagel Condensation and Transesterification Reactions
}

\author{
Bingbing Mi ${ }^{1,2}$, Xiufang Chen ${ }^{2}$, Changle Jiang ${ }^{3}$, Jingxin Wang ${ }^{3}$, Xiujuan Chen ${ }^{4}$, Bo Zhang ${ }^{2}$, \\ Xianmiao Liu ${ }^{1}$, Zhijia Liu ${ }^{1, *}$ and Benhua Fei ${ }^{1, *}$ \\ 1 International Centre for Bamboo and Rattan, Beijing 100102, China; mibingbing@icbr.ac.cn (B.M.); \\ liuxm206@163.com (X.L.) \\ 2 Key Laboratory of Bio-based Materials, Qingdao Institute of Bioenergy and Bioprocess Technology, \\ Chinese Academy of Sciences, Qingdao 266101, China; chenxf@qibebt.ac.cn (X.C.); boewse@163.com (B.Z.) \\ 3 School of Natural Resources, West Virginia University, Morgantown, WV 26506, USA; \\ chjiang@mix.wvu.edu (C.J.); Jingxin.Wang@mail.wvu.edu (J.W.) \\ 4 Material Science and Engineering, Benjamin M. Statler College of Engineering and Mineral Resources, \\ West Virginia University, Morgantown, WV 26506, USA; xc0001@mix.wvu.edu \\ * $\quad$ Correspondence: liuzj@icbr.ac.cn (Z.L.); feibenhua@icbr.ac.cn (B.F.); Tel.: +86-10-8478-9869 (Z.L.)
}

Received: 30 April 2018; Accepted: 29 May 2018; Published: 04 June 2018

\begin{abstract}
Highly porous nitrogen-doped carbons derived from bamboo shoots (BSNCs) were prepared through an in-situ synthesis method. The results showed that BSNCs had a large specific surface area, a relatively high nitrogen content and hierarchically porous structures. The catalytic properties of BSNCs were evaluated based on Knoevenagel condensation and transesterification reactions. Deprotonated BSNC-700 exhibited high efficiency for the model reactions as a solid base catalyst, and the superior sample deprotonated in $\mathrm{tBuOK}$ solution with a concentration of 0.1 increased the conversion rate from $16.1 \%$ to $76.0 \%$ for Knoevenagel condensation. The two reactions proceeded smoothly in the presence of deprotonated BSNC-700. The results also showed that the catalyst could be recycled for several times for Knoevenagel condensation. The results from this research will provide a guideline to develop bamboo shoot as a precursor to fabricate a superb solid base catalyst.
\end{abstract}

Keywords: bamboo shoot; nitrogen doped; solid base catalyst; Knoevenagel condensation; transesterification

\section{Introduction}

Chemical transformations processed by catalysts are widely used in the synthesis of natural and therapeutic drugs, polymer and cosmetics [1]. In general, the process is often acid-catalyzed and base-catalysed to control the organic reactions and achieve the desired goal. Studies have reported numbers of acid-catalysts, such as $\mathrm{TsOH}_{-} \mathrm{SiO}_{2}$ [2], $\mathrm{InCl}_{3}$ [3], $\left[\mathrm{Et}_{3} \mathrm{NH}\right]\left[\mathrm{HSO}_{4}\right]$ [4], rare-earth metal triflates [5], Meldrum's acid [6] and others. Over the past few decades, there have been many reports about acid catalysts but less about base catalysts, especially the solid base catalyst. In order to make the materials stable, recyclable and highly efficient, researchers have found solid base catalysts for the green catalytic process, such as the solid base catalysts for Knoevenagel condensation and transesterification reactions to prolong carbon-carbon bond. For solid base catalysts, the precursors included metal oxides [7,8], chitosan [9], doped or bimetal oxides [10,11], carbon nanotubes [12], apatites [13], clay minerals [14] and resin solid base catalysts [15,16]. Recently, doping hetero atoms into carbons (especially the nitrogen atom) can improve catalytic performance. Porous 
nitrogen-doped carbons as solid base catalysts are well known due to their catalytic properties and are used as support in heterogeneous catalysis [17]. The existence of nitrogen atoms in the carbon nanostructure has improved the efficiency of Knoevenagel condensation and transesterification reactions [18]. Some studies confirmed that the content and types of nitrogen affected the basic catalytic performance of porous carbons [19-23]. For example, Kan-Nari et al. found that while nitrogen-doped carbon materials were prepared by the ammoxidation of commercial carbon sources (carbon black and activated carbon), acting as base catalysts for Knoevenagel condensation and transesterification reactions, the nitrogen-doped onto the carbon surfaces played an important role in the catalystic activities [24]. Van Dommele et al. confirmed that the amount of pyridinic nitrogen in nitrogen-containing carbon nanotubes as solid base catalyst influenced the activities for Knoevenagel condensation [25]. Cao et al. reported a 99\% yield of the products for Knoevenagel condensation by amines functionalized $\mathrm{C}_{60}$ as solid base catalyst with ethanol [26].

In recent years, porous nitrogen-doped carbon materials derived from biomass has gained much attention because the sources are abundant, cheap and renewable $[27,28]$. In this study, bamboo shoot is chosen as a precursor because it is a kind of rapidly growing biomass material and is widely planted in China [29]. Bamboo shoots also have abundant carbohydrate, amino acids and nucleotides [30]. It can provide enough nitrogen source by itself for fabricating nitrogen-doped carbons during the calcination process. The authors found that the content of carbon and nitrogen in the dry weight of bamboo shoot is up to $41.67 \%$ and $4.27 \%$. To the best of the authors' knowledge, however, there is a lack of sufficient information utilizing bamboo shoot as a precursor to prepare nitrogen-doped carbons and few studies have used them as solid base catalysts for Knoevenagel condensation and transesterification reactions. Therefore, porous nitrogen-doped carbons derived from bamboo shoot (BSNCs) were prepared by simultaneously carbonizing and activating it without additional nitrogen sources. The obtained BSNCs were used as solid base catalysts to promote $\mathrm{C}-\mathrm{C}$ coupling reactions in Knoevenagel condensation and transesterification reactions. The results from this research will provide a guideline to develop porous nitrogen-doped carbons derived from bamboo shoot as a superb solid base catalyst.

\section{Results and Discussion}

\subsection{Catalyst Activity of the Carbon Materials for Knoevenagel Condensation}

The influence of treatments, such adding $\mathrm{KHCO}_{3}$ or not as well as the different calcination temperatures, were discussed using the obtained carbon materials and Knoevenagel condensation of benzaldehyde with malononitrile as a model reaction. The results are shown in Table 1. The reaction without adding catalyst between benzaldehyde and malononitrile at temperature of $70{ }^{\circ} \mathrm{C}$ in $\mathrm{CH}_{3} \mathrm{CN}$ solvent had a yield of $54.5 \%$ (entry one), but the selectivity of the target product was only $13.3 \%$ and mostly generated benzoic acid, which was attributed to the auto-oxidization of benzaldehyde in air. The catalytic activity of commercially activated carbon and BS-700 were relatively low (entries two to three). The selectivity of the target product was almost zero for commercially activated carbon. When BSNCs were used as catalyst, the selectivity increased up to $100 \%$, but the conversion was still low. The raw BSNCs were therefore less active for the present Knoevenagel condensation. The maximum ECC yield of $16.1 \%$ was found in BSNC-700. This phenomenon would be related to the porosities and functional groups on the surface of the nitrogen-doped carbons. 
Table 1. Knoevenagel condensation between benzaldehyde and malononitrile in the presence of various catalysts.

\begin{tabular}{|c|c|c|c|}
\hline Entry & Catalyst & Benzaldehyde Conversion (\%) & Target Product Selectivity (\%) \\
\hline 1 & / & 54.5 & 13.3 \\
\hline 2 & BS-700 & 2.2 & 100 \\
\hline 3 & Commercial activated carbon & 7.5 & 0 \\
\hline 4 & BSNC-600 & 8.3 & 100 \\
\hline 5 & BSNC-700 & 16.1 & 100 \\
\hline 6 & BSNC-800 & 8.2 & 100 \\
\hline
\end{tabular}

Table 2 shows the physicochemical properties of the obtained carbon materials. It was found that there were few pores on the surface of bamboo shoot (the specific surface area was only $0.4 \mathrm{~m}^{2} \mathrm{~g}^{-1}$ ). When bamboo shoot particles were directly carbonized at a temperature of $700{ }^{\circ} \mathrm{C}$ (BS-700), the specific surface area changed little $\left(4.6 \mathrm{~m}^{2} \mathrm{~g}^{-1}\right)$ and the type of the pore was mainly mesopore with the size of $7.13 \mathrm{~nm}$. When bamboo shoots particles were simultaneously carbonized and activated using $\mathrm{KHCO}_{3}$ at the designated temperature and time, the specific surface area, pore volume and pore size of BSNCs changed when the temperature increased from 600 to $800{ }^{\circ} \mathrm{C}$. The specific surface area of BSNC-600, BSNC-700 and BSNC-800 were 962, 1475 and $2271 \mathrm{~m}^{2} \mathrm{~g}^{-1}$, respectively. Similarly, the pore volume of BSNC-600, BSNC-700 and BSNC-800 were $0.48,0.73,1.25 \mathrm{~cm}^{3} \mathrm{~g}^{-1}$. Furthermore, the pore size distribution of BSNCs did not change so much from the temperature of 600 to $800{ }^{\circ} \mathrm{C}$. Although BSNC-700 had a smaller specific surface area $\left(1475 \mathrm{~m}^{2} \mathrm{~g}^{-1}\right)$ than BSNC-800's $\left(2271 \mathrm{~m}^{2} \mathrm{~g}^{-1}\right)$, the former was more active than the latter for Knoevenagel condensation. Conversely, BSNC-700 was more active than BSNC-600 with the increasing specific surface area. Figure 1 shows that the sorption types of BSNCs were I isotherm, indicating that there were abundant micropores and mesopores in BSNCs. It is well known that micropores are significantly influenced by the specific surface area and mesopores are influenced by pore volume [31]. At a relatively low pressure $(<0.3)$ there was a sharp increase, indicating the presentence of micropores. Then there was a relatively stable trend (0.3-0.9), indicating the existence of mesopores. There was also a tailing phenomenon around the pressure of one, indicating the existence of macropores. The results indicated that BSNCs had hierarchical pore structures. The pore size distribution curves also confirmed that micropores and mesopores existed in BSNCs. The above features can be confirmed that surface area is not the significant difference in the catalytic activity among the various prepared catalysts, which depend on the activator and calcination conditions. The surface chemical properties of BSNCs would be responsible for the catalyst activities, as will be discussed in the following.
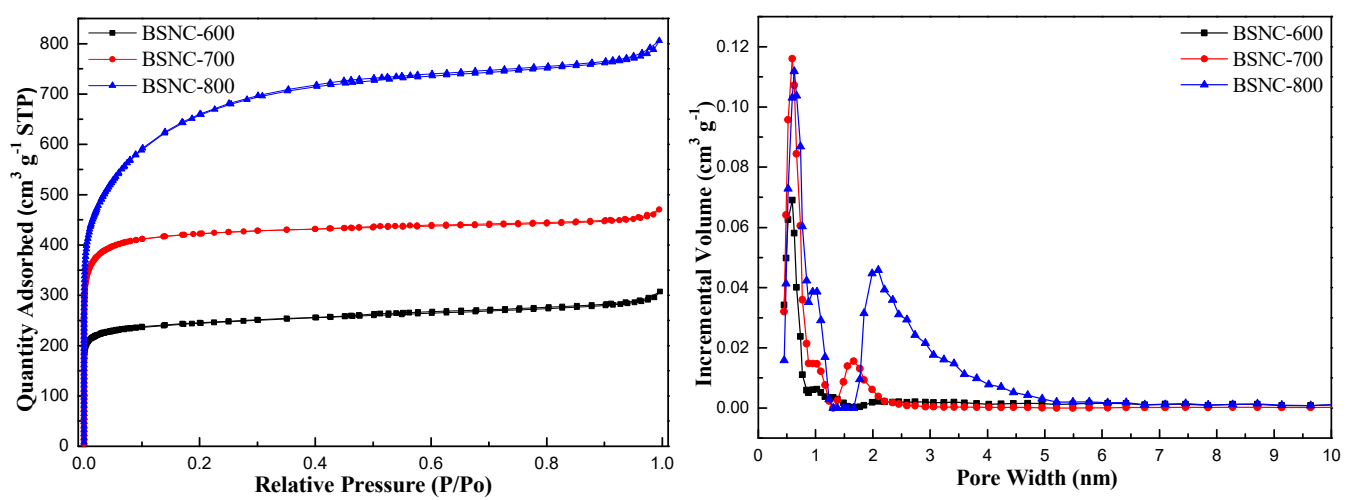

Figure 1. Nitrogen adsorption-desorption isotherm and pore size distribution. 
Table 2. The physicochemical properties of the obtained carbon materials.

\begin{tabular}{|c|c|c|c|c|c|c|c|c|}
\hline Samples & $\begin{array}{c}\text { Specific } \\
\text { Surface Area } \\
\left(\mathrm{m}^{2} \mathrm{~g}^{-1}\right)\end{array}$ & $\begin{array}{l}\text { Pore Volume } \\
\left(\mathrm{cm}^{3} \mathrm{~g}^{-1}\right)\end{array}$ & $\begin{array}{l}\text { Pore Size } \\
\text { (nm) }\end{array}$ & $\begin{array}{c}\mathrm{C}^{\mathrm{a}} \\
\text { (wt. } \%)\end{array}$ & $\begin{array}{l}\mathrm{N}^{\mathrm{a}} \\
\text { (wt.\%) }\end{array}$ & $\begin{array}{l}\text { Surface } O^{b} \\
\text { (at.\%) }\end{array}$ & $\begin{array}{c}\text { Surface } \mathbf{N}^{\mathbf{b}} \\
\quad \text { (at.\%) }\end{array}$ & $\mathrm{N}^{\mathrm{b}} / \mathrm{O}^{\mathrm{b}}$ \\
\hline Bamboo shoot & 0.4 [32] & $0.002[32]$ & 1 & 41.67 & 4.27 & I & I & I \\
\hline BS-700 & 4.6 & 0.01 & 7.13 & 63.36 & 4.40 & 18.3 & 6.10 & 0.333 \\
\hline BSNC-600 & 962 & 0.48 & 1.97 & 69.18 & 4.65 & 13.31 & 4.56 & 0.343 \\
\hline BSNC-700 & 1475 & 0.73 & 1.97 & 80.37 & 2.79 & 7.41 & 4.92 & 0.664 \\
\hline BSNC-800 & 2271 & 1.25 & 2.19 & 43.43 & 1.06 & 10.53 & 3.73 & 0.354 \\
\hline
\end{tabular}

The porous carbon materials were further examined by an elemental analyzer and X-ray Photoelectron Spectroscopy (XPS), which could be estimated that the carbons were nitrogen-doped by itself. As shown in Table 2, the raw material has a relatively high $\mathrm{N}$ content of $4.27 \%$, which is helpful to prepare biomass-based nitrogen-doped carbons. When the bamboo shoot simultaneously carbonized and activated with $\mathrm{KHCO}_{3}$, the $\mathrm{N}$ content of $\mathrm{BSNC}$ decreased from $4.65 \%$ to $1.06 \%$ with an increasing temperature from $600{ }^{\circ} \mathrm{C}$ to $800{ }^{\circ} \mathrm{C}$. This was because organic compounds probably formed $\mathrm{NO}, \mathrm{NO}_{2}$ or other nitrogen containing gases during the calcination process. This coincided with the results of the references $[33,34]$, which showed that the temperature caused thermal decomposition of the nitrogen groups.

XPS spectra in N1s region of the hierarchical nitrogen-doped carbons (Figure 2) and the relative amounts of nitrogen species obtained by deconvolution the total area of the N1s spectra are showed in Table 3. Compared with the strong peak of around $398.5 \mathrm{eV}$ of BS-700, the percent of pyridine $\mathrm{N}$ of BSNC-600, BSNC-700, BSNC-800 decreased, indicating that chemical treatment played a role in the preparation process of the carbons. Among BSNC-600, BSNC-700 and BSNC-800, the percent of pyridine $\mathrm{N}$ slightly increased with the increasing calcination temperature. This was attributed to the rearrangement in $\mathrm{C}-\mathrm{N}$ bond at elevated temperatures [19]. The fraction of pyrrolic $\mathrm{N}(400.3 \mathrm{eV})$ was the highest among the four nitrogen species. The different states of nitrogen-doped carbons had the different catalytic activity [35]. However, it is difficult to confirm the type of nitrogen-doped that played the role in the catalytic active sites. Previous reports [18] concluded that for nitrogen-containing carbon nanotubes fabricated by chemical vapor deposition of $\mathrm{C}$ - and $\mathrm{N}$-containing precursors, the initial activity increased with the amount of pyridine-type nitrogen in Knoevenagel condensation. The binding energy of pyrrolic $\mathrm{N}$ was relatively lower than quaternary $\mathrm{N}$ and $\mathrm{N}$-oxide, indicating that the electron density was lower and had a weaker Lewis basicity. Other types of nitrogen may also contribute to the basic active site for Knoevenagel condensation. There is an interesting relationship, given that the activity of BSNC-700 for Knoevenagel condensation has the highest N/O atomic ratio. This indicates that the catalytic performance is related to the existence of $\mathrm{N}$ and $\mathrm{O}$ on the surface of the carbons. The cooperation between $\mathrm{N}$ and $\mathrm{O}$-containing sites could promote the model reaction. Based on the above analysis, BSNC-700 was chosen as the target sample in the following experiments. 

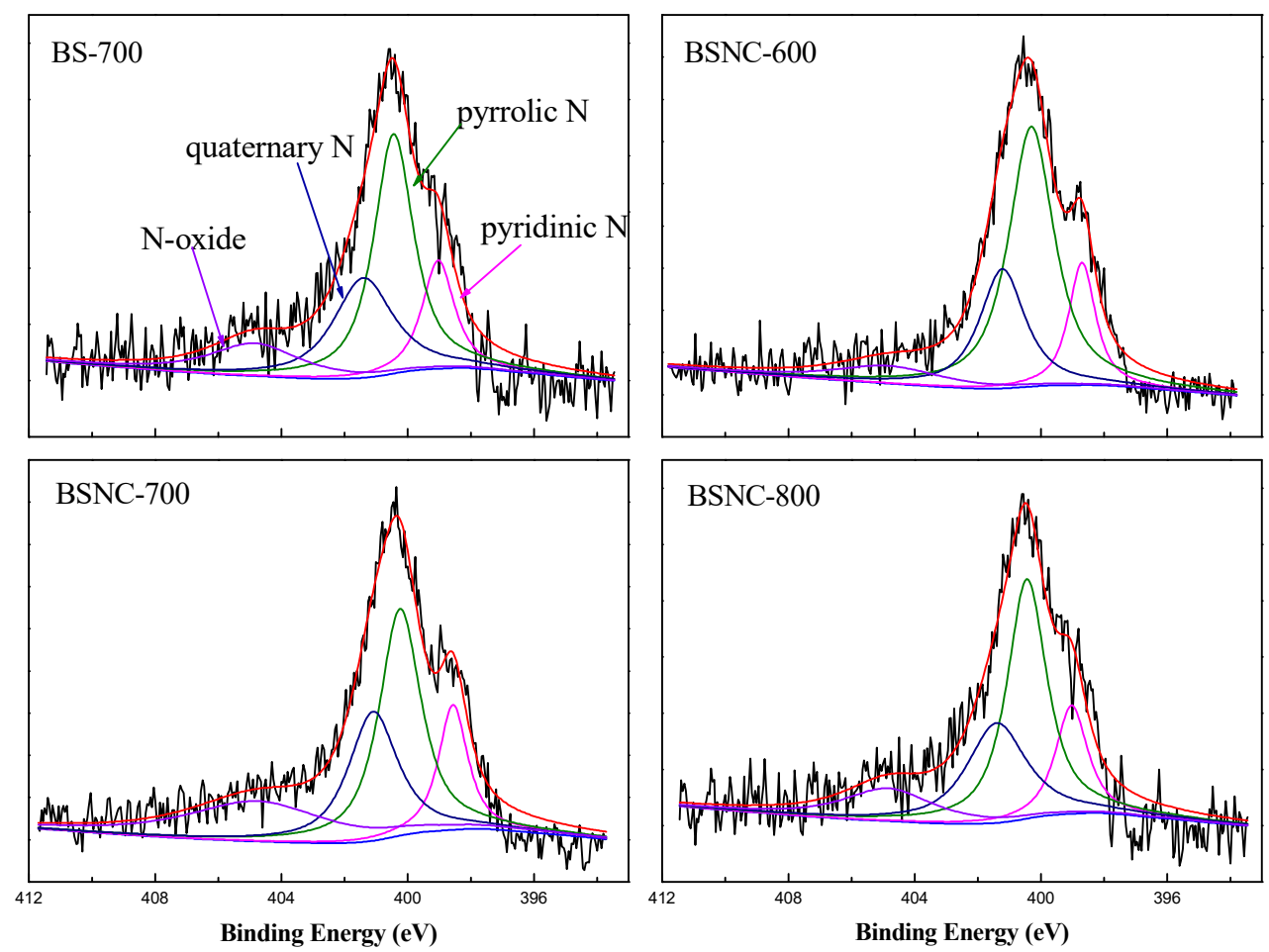

Figure 2. N1s spectra of the obtained carbons materials.

Table 3. Relative amounts of nitrogen species of the N1s spectra.

\begin{tabular}{ccccc}
\hline Samples & $\begin{array}{c}\text { Pyridinic N (\%) } \\
\mathbf{3 9 8 . 7} \mathbf{~ e V}\end{array}$ & $\begin{array}{c}\text { Pyrrolic N (\%) } \\
\mathbf{4 0 0 . 3} \mathbf{~ e V}\end{array}$ & $\begin{array}{c}\text { Quaternary N (\%) } \\
\mathbf{4 0 1 . 2} \mathbf{~ e V}\end{array}$ & $\begin{array}{c}\text { N-Oxide (\%) } \\
\mathbf{4 0 4 . 7} \mathbf{~ e V}\end{array}$ \\
\hline BS-700 & 18.1 & 43.6 & 19.9 & 18.4 \\
BSNC-600 & 14.0 & 58.8 & 19.1 & 8.1 \\
BSNC-700 & 14.4 & 37.6 & 25.4 & 22.6 \\
BSNC-800 & 15.9 & 43.5 & 27.0 & 13.6 \\
\hline
\end{tabular}

\subsection{Catalyst Activity of the Deprotonation of BSNC-700}

Even though the catalyst conversion of BSNC-700 was the highest among the obtained samples, it was not as effective as expected. In order to further improve the catalyst activity, the method of post-functioning was taken. BSNC-700 was treated with $\mathrm{HCl}, \mathrm{KOH}$ and $\mathrm{tBuOK}$ solutions. Table 4 showed the results of the various treatments for Knoevenagel condensation. When BSNC-700 was immersed in $\mathrm{HCl}$ solution $(1 \mathrm{M})$, that is, after BSNC-700 was protonated, the lowest conversion was found. This shows that the obtained nitrogen-doped carbons exhibited base. Therefore, the treatment with base solution would be an efficient method for deprotonation. When BSNC-700 was soaked in basic solution ( $\mathrm{KOH}$ or $\mathrm{tBuOK}$ ) with the concentration of $0.1 \mathrm{M}$ and $1 \mathrm{M}$, catalyst conversion of BSNC-700 increased from $16.1 \%$ to $32.2 \%$ (BSNC-700-OH with a concentration of $0.1 \mathrm{M}$ ), $34.4 \%$ (BSNC-700-OH with a concentration of $1.0 \mathrm{M}$ ), $76.0 \%$ (BSNC-700-tBu with a concentration of $0.1 \mathrm{M}$ ) and $79.9 \%$ (BSNC-700-tBu with a concentration of $1.0 \mathrm{M}$ ). It was found that the change of conversion of treated BSNC-700 was not obvious using the same base solution with different concentrations, but the conversion of BSNC-700 treated with $\mathrm{tBuOK}$ was obviously higher than that treated with $\mathrm{KOH}$ solution. The results suggested that the alkoxide base solution is more effective at deprotonating for BSNC-700 than hydroxide base solution when the solution concentration was same. In addition, under the same solution, the concentration had little influence on its catalytic efficiency. Thus, BSNC-700 soaked by $0.1 \mathrm{M} \mathrm{tBuOK}$ solution was used as the solid base catalyst in the following experiments. 
Table 4. Knoevenagel condensation of benzaldehyde with malononitrile by the deprotonation of BSNC-700.

\begin{tabular}{cccc}
\hline Entry & Catalysts & Benzaldehyde Conversion (\%) & Target Product Selectivity (\%) \\
\hline 1 & BSNC-700 & 16.1 & 100 \\
2 & BSNC-700-H (1.0 M) & 1.0 & 100 \\
3 & BSNC-700-OH (1.0 M) & 34.4 & 100 \\
4 & BSNC-700-OH (0.1 M) & 32.2 & 100 \\
5 & BSNC-700-tBu (1.0 M) & 79.9 & 100 \\
6 & BSNC-700-tBu (0.1 M) & 76.0 & 100 \\
\hline
\end{tabular}

When BSNC-700-tBu $(0.1 \mathrm{M})$ was used as the solid catalyst, the conversation of benzaldehyde was $79.9 \%$ and the selectivity of the target product was 100\%. The surface basicity of BSNC-700 and BSNC-700-tBu $(0.1 \mathrm{M})$ were determined according to a temperature programmed desorption of $\mathrm{CO}_{2}$ $\left(\mathrm{CO}_{2}\right.$-TPD) (Figure 3). There were three stages for the basic sites including temperature below $230{ }^{\circ} \mathrm{C}$, temperature between 230 and $400{ }^{\circ} \mathrm{C}$ and temperature above $400{ }^{\circ} \mathrm{C}$. It was found that BSNC-700 and BSNC-700-tBu $(0.1 \mathrm{M})$ had $\mathrm{CO}_{2}$ desorption peaks of around $160^{\circ} \mathrm{C}$ and $200^{\circ} \mathrm{C}$, which was attributed to the weak basic sites on the surface of $\mathrm{OH}$ function groups. Both samples had the same basic sites at $320{ }^{\circ} \mathrm{C}$ due to the tuning of $\mathrm{O}^{2-}$, respectively. However, the intensity of BSNC-700-tBu $(0.1 \mathrm{M})$ was higher than that of BSNC-700, which could be attributed to the treatment of $\mathrm{tBuOK}$ solution. When the temperature was above $400{ }^{\circ} \mathrm{C}$, there was little difference of basic site between the two samples. BSNC-700-tBu $(0.1 \mathrm{M})$ still had a relatively high basic site, which played an important role in the catalytic process. To eliminate the possible contribution of $\mathrm{K}$ ion derived from the base (tBuOK) on the surface of BSNC-700, XPS was used to investigate the existence of $\mathrm{K}$. The results showed that it could not find $\mathrm{K}$ on the sample of BSNC-700-tBu $(0.1 \mathrm{M})$, which suggested that $\mathrm{K}$ ion made no contribution for the catalytic performance.

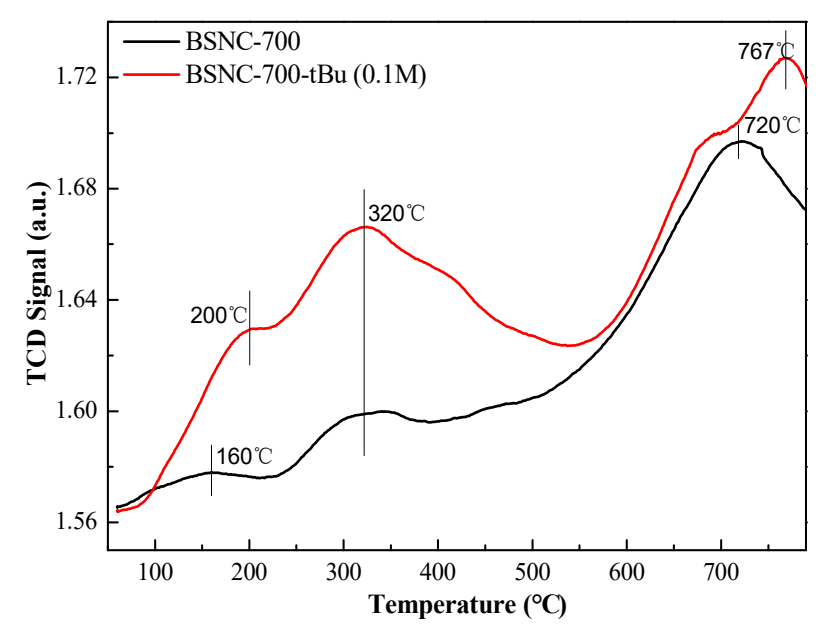

Figure 3. $\mathrm{CO}_{2}$-TPD curves of BSNC-700 and BSNC-700-tBu (0.1 M).

\subsection{Recyclability of BSNC-700-tBu (0.1 M)}

Recyclability is one of the important properties of the catalyst. In order to determine the recycling property of the catalyst for the Knoevenagel condensation, BSNC-700-tBu $(0.1 \mathrm{M})$ was used as the catalyst for the reaction of benzaldehyde and malononitrile at temperature of $70{ }^{\circ} \mathrm{C}$ for two hours. After the first reaction, the catalyst was separated then washed with ethanol and deionized water. Then the catalyst was dried at temperature of $70{ }^{\circ} \mathrm{C}$ for next recycling use. Figure 4 showed the catalyst activities during five successive reactions. The catalyst was found to decrease its activity in the second run. The main reason was the formation of organic acids, such as benzoic acid, 
which covered the exposed base sites and decreased its activity. When the catalyst was washed using $0.1 \mathrm{M}$ tBuOK solution, it obviously recovered its catalyst activity. This indicated that the basic solution could remove the organic acids existed on the surface of catalyst. The results also confirmed that BSNC-700-tBu $(0.1 \mathrm{M})$ was recyclable as the base catalyst.

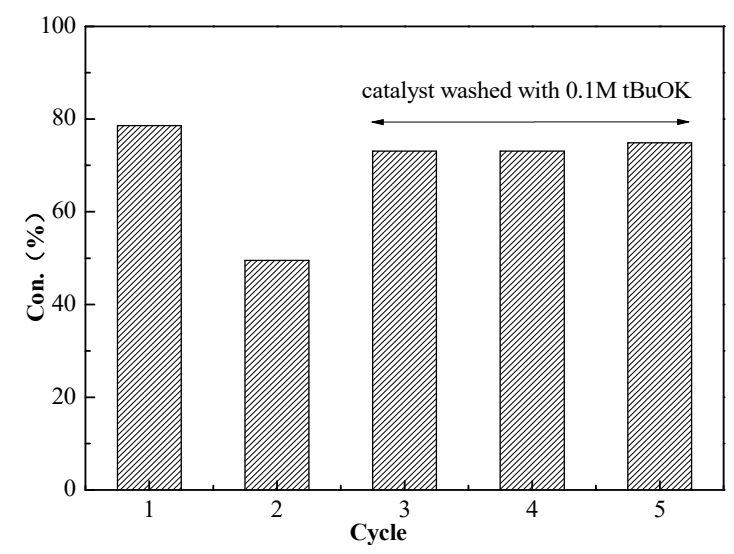

Figure 4. Variation of Knoevenagel condensation between benzaldehyde and malononitrile during five consecutive catalytic uses with BSNC-700-tBu (0.1 M).

\subsection{The Catalyst Activities of BSNC-700-tBu (0.1 M) for Transesterification Reactions}

The performance of BSNC-700-tBu $(0.1 \mathrm{M})$ as an active solid base catalyst was further tested for transesterification reactions of ethyl acetoacetate with different alcohols under the temperature of $110{ }^{\circ} \mathrm{C}$ for $16 \mathrm{~h}$. As shown in Table 5, ethyl acetoacetate could be transesterfied into the corresponding esters except when 1-methylcyclohexanol was the substrate. When an unsaturated alcohol, such as cinnamyl alcohol, was used, BSNC-700-tBu $(0.1 \mathrm{M})$ had a relatively high conversion and selectivity. 1-Hexanol, as the present of long-chain, BSNC-700-tBu $(0.1 \mathrm{M})$ also had a high conversion of $74.4 \%$. Compared with cyclic alcohol which had a hindered alcohol group, the long-chain alcohols were easier to form the corresponding esters. However, when BSNC-700-tBu $(0.1 \mathrm{M})$ was applied to catalyze the transesterification reactions, it needed a long time to get a high conversion and the former model reaction went more smoothly than when BSNC-700-tBu $(0.1 \mathrm{M})$ was used as the base catalyst.

Table 5. Transesterification reactions catalyzed by BSNC-700-tBu (0.1 M).

Entry




\section{Materials and Methods}

\subsection{Preparation of BSNCs}

Bamboo shoots were taken from Zhejiang Province, China. After removing the scale-like outer layers, bamboo shoots were cut into slices and dried at temperature of $70{ }^{\circ} \mathrm{C}$ for $12.0 \mathrm{~h}$ in the oven. Then the bamboo shoots were ground into powder using a Wiley Mill and screened to 250-425 $\mu \mathrm{m}$ particles.

Two grams of bamboo shoot particles and $8.0 \mathrm{~g} \mathrm{KHCO}_{3}$ were dissolved in $25 \mathrm{~mL}$ deionized water. Then the bamboo shoot particles were ultrasound-treated and freeze-dried until they mass stabilized. They were calcined in a tube furnace at the target temperature of $600{ }^{\circ} \mathrm{C}, 700{ }^{\circ} \mathrm{C}$ and $800{ }^{\circ} \mathrm{C}$ for $1.0 \mathrm{~h}$ under $\mathrm{N}_{2}$ atmosphere respectively. The heating rate was $10{ }^{\circ} \mathrm{C} \mathrm{min}{ }^{-1}$ with a nitrogen flow rate of $100 \mathrm{~mL} \mathrm{~min}^{-1}$. The process was showed in Figure 5. The obtained carbons were filtered, washed with deionized water and dried at temperature of $70^{\circ} \mathrm{C}$ in the oven. Samples were placed into separate Ziploc bags and sealed tightly. The obtained samples were labeled as BSNC-600, BSNC-700, BSNC-800 and the sample without adding $\mathrm{KHCO}_{3}$ and carbonized at temperature of $700{ }^{\circ} \mathrm{C}$ under $\mathrm{N}_{2}$ atmosphere was labeled as BS-700.

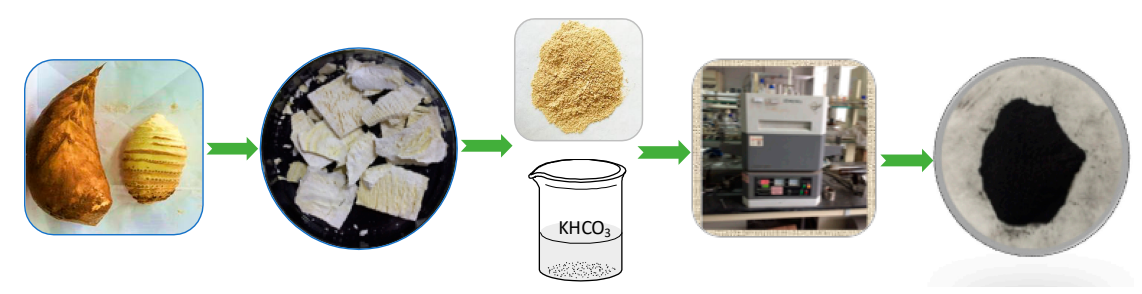

Figure 5. The preparation process of the nitrogen-doped carbon materials.

\subsection{Catalytic Test}

The catalytic activities of the as-prepared nitrogen-doped carbon materials were tested for Knoevenagel condensation and transesterification reactions using a thick wall pressure flask in an oil bath. For Knoevenagel condensation, $50 \mathrm{mg}$ of catalyst, $1 \mathrm{mmol}$ of benzaldehyde, $2 \mathrm{mmol}$ of malononitrile and $10 \mathrm{~mL}$ acetonitrile solvent were mixed into the flask. For transesterification reactions, $2 \mathrm{mmol}$ of ethyl acetate, $1 \mathrm{mmol}$ of ethanol, $50 \mathrm{mg}$ of catalyst and $10 \mathrm{~mL}$ of toluene solvent were mixed and the reaction temperature was set to $110{ }^{\circ} \mathrm{C}$. After the reaction, the mixture was filtered and toluene was added as an internal standard. The product identification was determined by Gas Chromatography (Shimadzu GC-2010, Kyoto, Japan) with a DB-5 capillary column coupled with a hydrogen flame detector (FID detector).

\subsection{Characterization}

The $\mathrm{C}, \mathrm{H}$ and $\mathrm{N}$ content of the obtained carbons were determined by an elemental analyzer (Vario EL IIICHNS, Elementar, Langenselbold, Germany).

X-ray Photoelectron Spectroscopy (XPS) (Thermo Scientific Escalab 250Xi, Thermo Fisher Scientific, Waltham, MA, USA) was carried out using a Vacuum Generators XPS system operating with Al $(\mathrm{K} \alpha)$ radiation.

$\mathrm{N}_{2}$ adsorption-desorption analyses were determined on a sorption analyzer (Quantachrome Autosorb 2020, Quantachrome, Boynton Beach, FL, USA). Samples were degassed at a temperature of $180^{\circ} \mathrm{C}$ for $6.0 \mathrm{~h}$ and analyzed at temperature of $77 \mathrm{~K}$. The Brunauer-Emmett-Teller (BET) method, $t$-plot method and non-local density functional theory (NLDFT) were used to calculate the specific surface area, pore volume and pore distribution.

The basic properties of the samples were tested on a temperature programmed desorption of $\mathrm{CO}_{2}$ (CO 2 -TPD) (Micromeritics AutoChem II 2920, Micromeritics, Norcross, GA, USA). 


\section{Conclusions}

A simple and available method through in-situ synthesis route was found to prepare highly porous nitrogen-doped carbons derived from bamboo shoot. The obtained carbons had a large specific surface area, a relative high nitrogen content, hierarchically porous structures and could be used as base catalysts for Knoevenagel condensation and transesterification reactions. When BSNC-700 was deprotonated by $\mathrm{tBuOK}$ with the concentration of $1.0 \mathrm{M}$, the catalytic performance could be improved from $16.1 \%$ to $79.9 \%$. BSNC-700-tBu $(0.1 \mathrm{M})$ was active and reached high yield of the target products. The catalyst was stable and could be recycled several times without the loss of catalytic activity for Knoevenagel condensation. It also proved that BSNC-700 can be used as a multifunctional catalyst for transesterification reactions. We expect that porous nitrogen-doped carbons derived from bamboo shoots can be used as a solid base catalyst in other organic reactions.

Author Contributions: B.F. and Z.L. designed the experiment. B.M. prepared the samples, B.M. and X.C. took characterization and data analysis, discussed with X.C., C.J., J.W., X.C., B.Z., X.L., B.M. wrote the manuscript. All authors reviewed the manuscript.

Acknowledgments: This research was financially funded by CAS Key Laboratory of Bio-based Materials, Qingdao Institute of Bioenergy and Bioprocess Technology, Chinese Academy of Science (Grant No. KLBM2016001), 'National Key R\&D Program of China' (Grant No. 2017YFD0600804) and 'Basic Scientific Research Funds of International Centre for Bamboo and Rattan-Manufacturing technology of biochar from mixture of bamboo and wood' (Grant No. 1632018020).

Conflicts of Interest: The authors declare no conflict of interest.

\section{References}

1. Ying, A.; Liu, L.; Wu, G.; Chen, X.; Ye, W. Knoevenagel condensation catalyzed by DBU Br(ö)nsted ionic liquid without solvent. Chem. Res. Chin. Univ. 2009, 25, 876-881.

2. Siddiqui, Z.N.; Tarannum, S. TsOH-SiO 2 , as an efficient and eco-friendly catalyst for Knoevenagel condensation. Tetrahedron Lett. 2014, 55, 2612-2617. [CrossRef]

3. Singh, M.S.; Raghuvanshi, K. Recent advances in $\mathrm{InCl}_{3}$-catalyzed one-pot organic synthesis. Tetrahedron 2012, 68, 8683-8697. [CrossRef]

4. Siddiqui, Z.N.; Khan, K. $\left[\mathrm{Et}_{3} \mathrm{NH}\right]\left[\mathrm{HSO}_{4}\right]$-catalyzed efficient, eco-friendly, and sustainable synthesis of quinoline derivatives via Knoevenagel condensation. ACS Sustain. Chem. Eng. 2014, 2, 1187-1194. [CrossRef]

5. Shu, K.; Masaharu, S.; Hidetoshi, K.; William, L. ChemInform Abstract: Rare-earth metal triflates in organic synthesis. Chem. Rev. 2002, 102, 2227-2302.

6. Mohite, A.R.; Bhat, R.G. A practical and convenient protocol for the synthesis of (E)- $\alpha, \beta$-unsaturated acids. Org. Lett. 2013, 15, 4564-4567. [CrossRef] [PubMed]

7. Liu, Z.; Cortés-Concepción, J.A.; Mustian, M.; Amiridis, M.D. Effect of basic properties of MgO on the heterogeneous synthesis of flavanone. Appl. Catal. 2006, 302, 232-236. [CrossRef]

8. Li, M.; Tang, M.; Deng, J.; Wang, Y. Nitrogen-doped flower-like porous carbon materials directed by in situ hydrolysed MgO: Promising support for Ru nanoparticles in catalytic hydrogenations. Nano Res. 2016, 9, 3129-3140. [CrossRef]

9. Sakthivel, B.; Dhakshinamoorthy, A. Chitosan as a reusable solid base catalyst for Knoevenagel condensation reaction. J. Colloid Interface Sci. 2017, 485, 75-80. [CrossRef] [PubMed]

10. Thitsartarn, W.; Kawi, S. An active and stable $\mathrm{CaO}-\mathrm{CeO}_{2}$ catalyst for transesterification of oil to biodiesel. Green Chem. 2011, 13, 3423-3430. [CrossRef]

11. Boey, P.L.; Maniam, G.P.; Hamid, S.A. Performance of calcium oxide as a heterogeneous catalyst in biodiesel production: A review. Chem. Eng. J. 2011, 168, 15-22. [CrossRef]

12. Yan, Y.; Miao, J.; Yang, Z.; Xiao, F.X.; Yang, H.B.; Liu, B.; Yang, Y. Carbon nanotube catalysts: Recent advances in synthesis, characterization and applications. Chem. Soc. Rev. 2015, 44, 3295-3346. [CrossRef] [PubMed]

13. Sebti, S.; Solhy, A.; Tahir, R.; Smahi, A. Modified hydroxyapatite with sodium nitrate: An efficient new solid catalyst for the claisen-schmidt condensation. Appl. Catal. A 2002, 235, 273-281. [CrossRef]

14. Wang, X.; Tseng, Y.H.; Chan, J.C.C.; Cheng, S. Catalytic applications of aminopropylated mesoporous silica prepared by a template-free route in flavanones synthesis. J. Catal. 2005, 233, 266-275. [CrossRef] 
15. Marchetti, J.M.; Errazu, A.F. Biodiesel production from acid oils and ethanol using a solid basic resin as catalyst. Biomass Bioenergy 2010, 34, 272-277. [CrossRef]

16. Liu, F.; Li, W.; Sun, Q.; Zhu, L.; Meng, X.; Guo, Y.H.; Xiao, F.S. Transesterification to biodiesel with superhydrophobic porous solid base catalysts. ChemSusChem 2011, 4, 1059-1062. [CrossRef] [PubMed]

17. Calvino-Casilda, V.; Lopez-Peinado, A.J.; Duran-Valle, C.J.; Martin-Aranda, R.M. Cheminform abstract: Last decade of research on activated carbons as catalytic support in chemical processes. Catal. Rev. 2010, 41, 325-380. [CrossRef]

18. Jin, X.; Balasubramanian, V.; Selvan, S.; Sawant, D.; Chari, M.; Lu, G.; Vinu, A. Highly ordered mesoporous carbon nitride nanoparticles with high nitrogen content: A metal-free basic catalyst. Angew. Chem. 2009, 48, 7884-7887. [CrossRef] [PubMed]

19. Goyal, R.; Sarkar, B.; Sameer, S.; Singhal, N.; Bordoloi, A. Role of pyridinic nitrogen on base catalyzed knoevenagel condensation over pristine CNx. ChemistrySelect 2017, 2, 8086-8090. [CrossRef]

20. Fujita, S.I.; Katagiri, A.; Watanabe, H.; Asano, S.; Yoshida, H.; Arai, M. Preparation of nitrogen-doped carbon from polyacrylonitrile and its application as a solid-base catalyst. ChemCatChem 2015, 7, 2965-2970. [CrossRef]

21. Makowski, P.; Weber, J.; Thomas, A.; Goettmann, F. A mesoporous poly(benzimidazole) network as a purely organic heterogeneous catalyst for the Knoevenagel condensation. Catal. Commun. 2009, 10, 243-247. [CrossRef]

22. Wei, Z.; Chen, Y.; Wang, J.; Su, D.; Tang, M.; Mao, S.; Wang, Y. Cobalt encapsulated in N-doped graphene layers: An efficient and stable catalyst for hydrogenation of quinoline compounds. ACS Catal. 2016, 6, 5816-5822. [CrossRef]

23. Ansari, M.B.; Jin, H.; Parvin, M.N.; Park, S.E. Mesoporous carbon nitride as a metal-free base catalyst in the microwave assisted Knoevenagel condensation of ethylcyanoacetate with aromatic aldehydes. Catal. Today 2012, 185, 211-216. [CrossRef]

24. Kan-Nari, N.; Okamura, S.; Fujita, S.I.; Ozaki, J.I.; Arai, M. Nitrogen-doped carbon materials prepared by ammoxidation as solid base catalysts for Knoevenagel condensation and transesterification reactions. Adv. Synth. Catal. 2010, 352, 1476-1484. [CrossRef]

25. Van, D.S.; Jong, K.P.D.; Bitter, J.H. Nitrogen-containing carbon nanotubes as solid base catalysts. Chem. Commun. 2006, 46, 4859-4861.

26. Sun, Y.B.; Cao, C.; Huang, P.; Yang, S.; Song, W. Amines functionalized c60 as solid base catalysts for knoevenagel condensation with high activity and stability. RSC Adv. 2015, 5, 86082-86087. [CrossRef]

27. Karagoz, S.; Tay, T.; Ucar, S.M. Activated carbons from waste biomass by sulfuric acid activation and their use on methylene blue adsorption. Bioresour. Technol. 2008, 99, 6214-6222. [CrossRef] [PubMed]

28. Kai, W.; Ning, Z.; Lei, S.; Rui, Y.; Tian, X.; Wang, J.; Song, Y.; Xu, D.; Guo, Q.; Liu, L. Promising biomass-based activated carbons derived from willow catkins for high performance supercapacitors. Electrochim. Acta 2015, 166, 1-11.

29. Guo, S.; Dong, X.; Zhu, C.; Han, Y.; Ma, F.; Wu, T. Pyrolysis behaviors and thermodynamics properties of hydrochar from bamboo (phyllostachys heterocycla cv. pubescens) shoot shell. Bioresour. Technol. 2017, 233, 92-98. [CrossRef] [PubMed]

30. Sun, J.; Ding, Z.Q.; Gao, Q.; Xun, H.; Tang, F.; Xia, E.D. Major chemical constituents of bamboo shoots (Phyllostachys pubescens): Qualitative and quantitative research. J. Agric. Food Chem. 2016, 64, 2498-2505. [CrossRef] [PubMed]

31. Torii, S.; Jimura, K.; Hayashi, S.; Kikuchi, R.; Takagaki, A. Utilization of hexagonal boron nitride as a solid acid-b bifunctional catalyst. J. Catal. 2017, 355, 176-184. [CrossRef]

32. Chen, X.F.; Zhang, J.Y.; Zhang, B.; Dong, S.M.; Guo, X.C.; Mu, X.D.; Fei, B.H. A novel hierarchical porous nitrogen-doped carbon derived from bamboo shoot for high performance supercapacitor. Sci. Rep. 2017, 7, 7362. [CrossRef] [PubMed]

33. Pels, J.R.; Kapteijn, F.; Moulijn, J.A.; Zhu, Q.; Thomas, K.M. Evolution of nitrogen functionalities in carbonaceous materials during pyrolysis. Carbon 1995, 33, 1641-1653. [CrossRef]

34. Sevilla, M.; Parra, J.B.; Fuertes, A.B. Assessment of the role of micropore size and N-doping in $\mathrm{CO}_{2}$ capture by porous carbons. ACS Appl. Mater. Interfaces 2013, 5, 6360-6368. [CrossRef] [PubMed]

35. Ikeda, T.; Boero, M.; Huang, S.F.; Terakura, K.; Oshima, M.; Ozaki, J. Carbon alloy catalysts: Active sites for oxygen reduction reaction. J. Phys. Chem. C 2008, 112, 14706-14709. [CrossRef]

(C) 2018 by the authors. Licensee MDPI, Basel, Switzerland. This article is an open access article distributed under the terms and conditions of the Creative Commons Attribution (CC BY) license (http://creativecommons.org/licenses/by/4.0/). 